\title{
A SUSTENTABILIDADE (?) DA CANA-DE-AÇÚCAR NO BRASIL
}

\author{
Thiago Souza Silveira ${ }^{1}$
}

RESUMO: O presente trabalho visa a reflexão sobre a indústria sucroenergética do Brasil, em específico sobre as questões sociais e ambientais. Um ramo tão competitivo, que coloca o Brasil como vanguarda dos países com tecnologia de produção de energia renovável, merece um enfoque maior para entendermos as transformações que ela traz na esteira do progresso que leva à região onde se instala. Observando o aumento paulatino na demanda pelo subprodutos da cana-de-açúcar, em especial o etanol, conhecendo melhor sobre como acontece esse novo processo dinâmico para as cidades, ajudará a evitar os erros ocorridos nas décadas de 1970 e 1980. Este artigo pode auxiliar os tomadores de decisão e a sociedade na escolha pelo melhor caminho de desenvolvimento, principalmente na observação da indústria canavieira sob as diversas áreas do cotidiano, como a saúde, economia, trabalho e meio ambiente. Ao final há um balanço sobre o principal argumento governamental da cana sobre a sua real sustentabilidade e quanto a ser um produto ecologicamente correto.

Palavras-chave: Cana-de-açúcar. Sustentabilidade. Problemas ambientais.

\section{INTRODUÇÃO}

O Brasil foi um país predominantemente rural até meados do século XX. Seu potencial agrário é destacado desde o seu descobrimento nas cartas de Pero Vaz de Caminha. A cana-de-açúcar foi o primeiro grande investimento de Portugal na colônia, aproveitando a sua experiência nos Açores e llha da Madeira. Aqui temos um clima

\footnotetext{
${ }^{1}$ Mestrando em Geografia Física da Universidade de São Paulo. E-mail: thiagosousilveira@usp.br.
} 
favorável para o seu crescimento e amadurecimento, terras férteis e extensas no nordeste e em São Paulo, além de grande disposição de mão-de-obra - inicialmente escrava e depois imigrante - além da demanda grande pelos produtos da cana, o álcool, o açúcar e a cachaça. O ciclo do açúcar caiu no início do século XVIII, mas nada suficiente para se encerrar a produção de açúcar no país. Em meados do século XX, o mundo sofreu com a crise do petróleo em 1973 e 1979. Por isso, a presidência, durante a ditadura militar, resolveu criar o programa Pró-álcool, com a intenção de diversificar a matriz energética e reduzir a dependência do petróleo.

\section{PRÓ-ÁLCOOL - BREVE HISTÓRICO}

Com o incentivo do governo para a produção de motores movidos a etanol, em 1975 surgia o primeiro automóvel movido a etanol, imediatamente absorvido pelos brasileiros e sendo um sucesso de vendas. O pioneirismo do Brasil serviu para ajudar a sustentar politicamente a ditadura militar e aliviar a balança econômica, além de impulsionar os canavieiros com financiamento e garantia de mercado para a cana e também para a indústria automotiva. Na década de 1980 os automóveis movidos a etanol superaram os a gasolina, mas na década de 1990 foram quase extintos. Com o advento do motor bicombustível que poderia usar etanol, gasolina ou a mistura dos dois em qualquer proporção, o mercado de etanol se tornou novamente atrativo. (ÚNICA, 2012) 
Número de Carros 0Km Vendidos Segundo o Combustivel

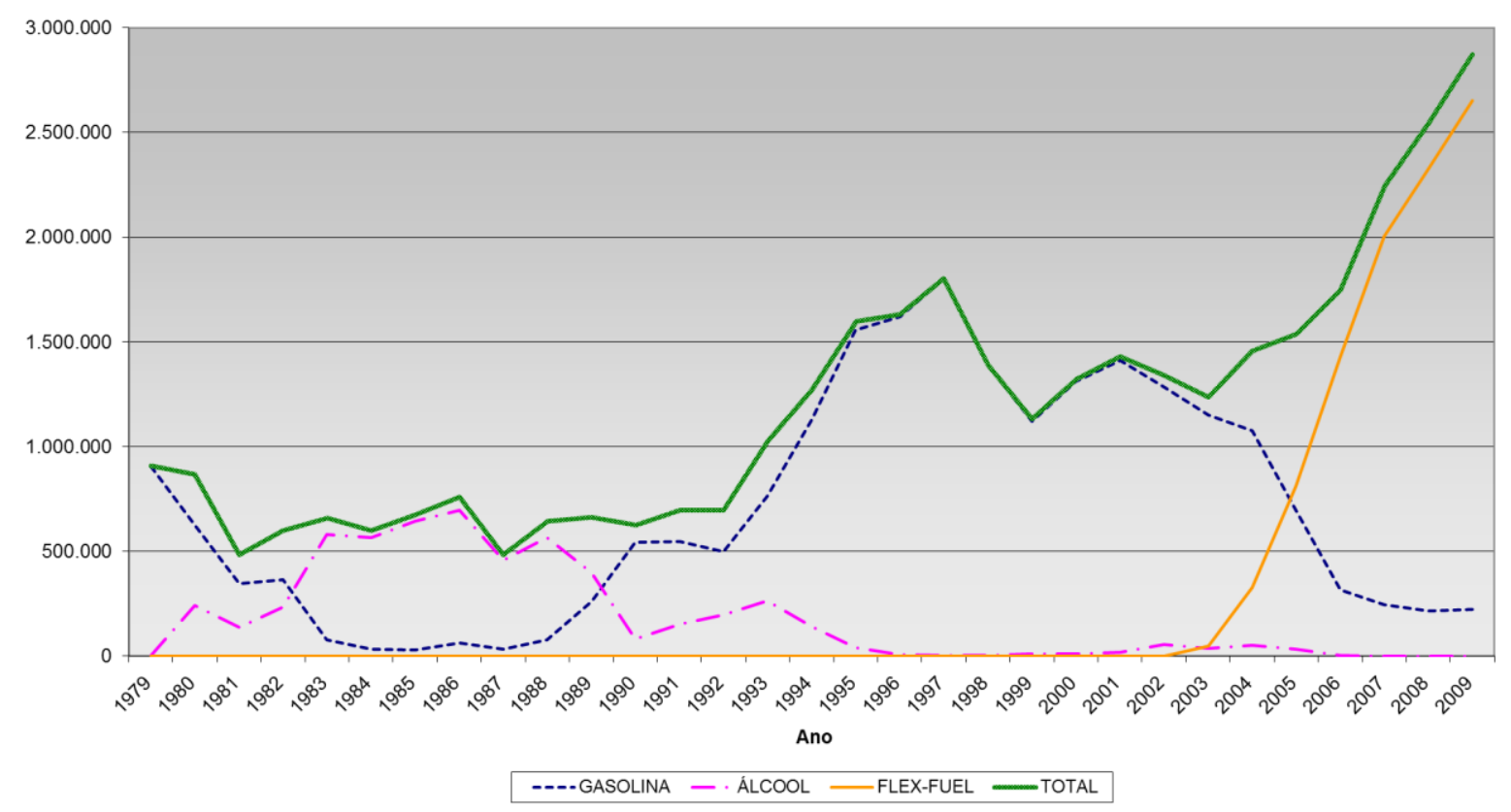

Tabela 1 - Fonte: ANFAVEA - Assos. Nacional de Fabricantes de Veículos Automotores.

\section{QUESTÕES POLÍTICAS DA CANA}

Nos Estados Unidos o etanol é produzido principalmente do milho, em outros lugares da Europa pode ser feito a partir da beterraba e também da batata. Sendo assim, por que o Brasil escolheu a cana-de-açúcar para produzir o etanol?

Historicamente, o setor primário do país é o mais significativo quando se trata de arrecadação de divisas. E quem tem o poder econômico, consegue muito mais facilmente o poder político também, por isso a chamada "bancada ruralista" - grupo de políticos ligados à defesa dos produtores e criadores - na crise do petróleo na década de 1970, em plena ditadura militar brasileira, mobilizou-se tendo em vista a oportunidade de promover novamente a cana, que andava em declínio e sempre foi muito tradicional no Brasil desde a colônia.

Muitos municípios têm a cana como sua principal fonte de arrecadação, e por isso, dependendo da condição do mercado, a própria cidade poderia quebrar economicamente. 
Dadas as condições de falência econômica de muitos municípios agrícolas, a crise do petróleo com iminência de racionamento de combustível como vinha ocorrendo no resto do mundo, a necessidade da sustentação dos militares no poder e a urgência por uma alternativa ao petróleo, o etanol da cana foi escolhido para se tornar a "salvação" do país da dependência do óleo.

Com esses argumentos, o governo federal destinou grandes linhas e financiamento para pesquisa e desenvolvimento de tecnologia, além do financiamento para plantio de cana para produção industrial de etanol nacional.

A partir de 1975, com a chegada do primeiro carro a etanol, as compras dispararam e os movidos a gasolina decaíram (tabela 1). Em 1993 o governo impôs a mistura de álcool à gasolina através da Lei 8.723 de 1993, justamente quando o setor de carros a etanol vinha passando por uma crise de vendas.

Analisando as alternativas, o programa Proálcool foi elaborado como plano de emergência para os choques do petróleo na década de 1970, incluindo aí também certo desespero, como relatado pelo jornal "O Globo" (3/09/2012). O então presidente do Banco Central, Carlos Langoni, viajou pela Arábia Saudita em 1982 com pedido pessoal do presidente Figueiredo para que não faltasse petróleo para o país e após penosas negociações, "O BC [Banco Central] deu uma garantia meramente virtual, porque não tínhamos reservas. Nosso único compromisso era comprar o petróleo deles", disse.

Se não fosse essa missão de Langoni, provavelmente teríamos um racionamento de combustível, e isso com certeza afetaria a popularidade do governo militar, já agonizante.

Com todas essas crises, a Petrobrás necessitou buscar petróleo em outros lugares, na plataforma continental, em águas profundas. Hoje a empresa é referência mundial na pesquisa e extração em grandes profundidades.

Enquanto o sustento político da economia era feito através da intermediação dos Estados Unidos, grandes empresários e também do aparelho repressor estatal, o governo militar ainda se mantinha de pé. Em troca do aumento da dívida externa com os Estados Unidos, preservação das riquezas dos mais ricos e também da "não-fiscalização" trabalhista das condições dos trabalhadores rurais, são pequenos exemplos da cumplicidade entre as camadas poderosas da sociedade e o governo. Mas as contenções de gastos e arrochos no poder aquisitivo da população fizeram com que mais tarde o governo não se sustentasse mais. 


\section{PROBLEMAS NAS QUESTÕES TRABALHISTAS}

As condições degradantes de trabalho dos cortadores de cana são insalubres e são historicamente conhecidas, desde a época da escravidão. De lá para cá, pouca coisa mudou, o governo nas décadas de 1970 e 1980 precisava desesperadamente de uma solução, para isso precisou abrir mão da fiscalização dessas áreas e foi omisso com essas condições péssimas de trabalho, e às vezes até trabalho escravo visto hoje em algumas áreas.

A técnica de corte de cana é outro ponto estagnado no tempo, primeiro se queima a cana, ela desidrata, fica mais fácil de cortar, mais leve e também afasta os animais peçonhentos do local. Por outro lado, o cortador deve cortar mais cana para poder ter a mesma pesagem, ele tem que fazer isso num ambiente ainda quente pelas chamas e poluído com materiais particulados.

No final do século $X X$, com a mecanização da agricultura nos países subdesenvolvidos, a colheita da cana passou a ser cada vez mais mecanizada. Se por um lado é a promessa do fim daquelas situações de penúria dos cortadores, por outro é a falta de expectativa de emprego que os assola, provocando o êxodo rural e abarrotando as cidades de desempregados. São dois lados para se pesar que desde os cercamentos dos campos na Inglaterra do século XVII não se tem uma solução pronta.

Outro argumento muito usado, e justo pelos canavieiros, é a parte ecológica, onde através da mecanização não haveria mais a necessidade de se queimar o canavial. O que não é dito é que também se pode colher cana queimada com máquinas e até com mais eficiência, sendo nessa condição o seu melhor rendimento. Vivemos num regime capitalista, e segundo ZANCUL (1998), um homem colhendo cana queimada rende pouco mais de 9 toneladas/dia, uma máquina rende 32,29 toneladas/dia. A mesma máquina com cana sem queimar rende apenas 25,41 toneladas/dia. No regime capitalista muito competitivo, com o mercado ainda precisando de muito etanol e açúcar, o que o agricultor escolherá? 
Uma máquina de colher cana custa perto de um milhão de reais segundo a última grande feira de produtos agrícolas (Agrishow 2012). A pressão para que se pague o quanto antes esse financiamento é enorme, a demanda pelo produto é grande, a usina não aceita cana depois de 48 horas de colhida, agricultura foi sempre um negócio de risco, pois nunca se sabe quando ocorrerá a próxima quebra de safra. Então, esses são argumentos que forçariam o produtor a continuar usando a queima do canavial como técnica e também a mecanizar sua fazenda, empurrando os problemas sociais para 0 estado.

\section{PROBLEMAS AMBIENTAIS}

Como citado anteriormente, os efeitos colaterais da cana não passam apenas pela questão social, mas também pela ambiental. A UNICA - União da Indústria de Cana de Açúcar - argumenta de forma relativamente certa que a cana não invade área de mata, mas sim áreas de pasto degradado em geral. Imaginem a transformação da paisagem que deve ter acontecido a partir de 1970 quando tudo se transformou em canavial de uma vez? Naquela época não se tinha estudos de impactos ambientais, muito menos a preocupação com a natureza, vista a urgência de se conseguir energia. Mas, pela experiência de casos de mudanças na paisagem de forma abrupta, impactos negativos sempre ocorrem.

O ciclo de queima diário pelos oito meses de colheita da cana impacta na saúde dos trabalhadores, como já relatado, e também na saúde dos moradores do entorno. Há vários estudos sobre como a fumaça afeta a saúde da população de forma negativa. BARROCAS (2002) fez experiências com pranchas de depósito para medir a quantidade de fuligem que caíam nas casas e constatou que havia um aumento dessas fuligens na época de colheita e que isso incomodava a população pelo nível de sujeira depositada em suas casas.

O argumento ecológico que se faz sobre a cana-de-açúcar não é $100 \%$ verdadeiro, uma vez que é usada a queima de biomassa na sua produção. Essa queima gera problemas respiratórios na população, podendo levar a óbito (ARBEX, 2001). A mesma 
pluma de poluição que incomoda os moradores próximos também é transportada para outros locais mais distantes e ainda não se sabe quais são os efeitos na qualidade do ar desses locais. Dependendo da recorrência desses eventos, isso pode provocar externalizações de problemas, sendo necessárias esferas mais altas do governo para resolver. Por exemplo, se o oeste e norte de São Paulo poluir o ar do sul de Minas, um estado poderia acionar o outro juridicamente. Assim como aconteceu com a Alemanha e Noruega no caso de chuvas ácidas na primeira metade do século XX após a morte de peixes no país nórdico por poluentes lançados na atmosfera pelos germânicos.

Em São Paulo já existe um programa de extinção da queimada no canavial, para se cumprir a legislação ambiental, mas ele é de longo prazo e pode passar por adiamentos. A Lei Estadual 11.241 de 2002 prevê o fim da prática para áreas mecanizáveis para 2021 e para áreas não mecanizáveis para 2031. Atualmente, 50\% das áreas mecanizáveis são queimadas e $90 \%$ das não mecanizáveis são incendiadas (DIARIO OFICIAL DO ESTADO, 2002). Apesar da boa intenção da lei, ela ainda deixa um prazo muito longo para o fim total da prática.

\section{A CANA É REALMENTE VERDE? E ELA É SUSTENTÁVEL?}

Essa é uma pergunta simples, porém de resposta complexa. É possível vender a matriz energética da cana como energia limpa? A resposta mais correta talvez seja, "sim, é possível, mas estamos longe de fazer isso no momento". O impacto da produção de cana é tão grande por atingir tantos setores, que realmente estamos longe de afirmar isso no momento. Algumas coisas são praticamente impossíveis de mudar, como o sistema financeiro capitalista, esse é o principal problema apontado por WAGNER (2000) no seu livro, e estando sobre ele montado toda a cadeia produtiva, tudo o que se fizer será superficial.

A indústria sucroenergética provoca mudanças grandes em cidades que nem sempre estão preparadas para tal. Como por exemplo:

- Mudar a principal fonte de renda do município; 
- Mudar a matriz energética de pequenas cidades em determinadas épocas do ano, com a queima do bagaço da cana e a venda deste para a concessionária distribuir na região;

- Modificar a elite político-econômica da região;

- Monopolizar a fonte de empregos da cidade, passando tudo a viver em torno das usinas;

- Mudanças da paisagem natural anterior por uma nova cultura;

- Problemas ambientais como qualidade do ar que antes não havia;

- Agravamento de problemas de saúde na população local.

Isso se sustenta ao longo do tempo? Os impactos ambientais são anulados para ser considerado ecologicamente correto? Ao longo dos anos de 2009 a 2011, o governo Lula viajou em missões diplomáticas para tentar convencer países desenvolvidos a comprar etanol da cana, sugerindo claramente que ele era limpo, sustentável e ecologicamente correto. Na prática, vemos países exportadores de energia muito ricos, como os do Oriente Médio - não vamos discutir como eles distribuem essas riquezas depois - e para o Brasil, isso deveria funcionar também.

As queimadas na plantação e a pluma de poluição deixada não permitem que se classifique $o$ etanol e nem a produção de energia elétrica a partir da queima do bagaço como ecologicamente corretas. Do mesmo jeito que as condições muitas vezes subumanas e até escravas a que os trabalhadores são expostos não permitem que seja chamado de modo sustentável de produção.

A dinâmica da região com a cana é completamente mudada, pois nota-se a criação de tensões entre grandes e pequenas propriedades, problemas na fixação do homem no campo, a mecanização que traz desemprego e especulação pela posse da terra. $A$ queimada realizada na época da colheita, com auge em julho, agosto e setembro, provoca incômodo na população e problemas de saúde, ainda que contestado em partes por NEVES e CONEJERO (2010), mas confirmada por BARROCAS (2002), ZANCUL (1998) e WAGNER (2000). 
A ideia nesse artigo não é crucificar os produtores de cana, mas sim estabelecer uma reflexão sobre o que é passado como um bom hábito e na verdade é carregado de problemas estruturais que precisam ser resolvidos e são deixados de lado desde os anos 1970. A diversidade energética é fundamental para o país, a inovação tecnológica, igualmente, assim como a vanguarda na produção e plantio de commodities. Porém esses pontos ainda devem ser discutidos e solucionados, ou no mínimo mitigados para que se tenha justiça social, fim dos conflitos no campo e condições de trabalho dignas para todos.

\section{BIBLIOGRAFIA}

ARBEX, M. A. Avaliação dos efeitos do material particulado proveniente da queima da plantação de cana-de-açúcar sobre a morbidade respiratória na população de AraraquaraSP. Tese de Doutorado, Faculdade de Medicina, Universidade de São Paulo, São Paulo, 2001.

BARROCAS, R. A queimada da cana-de-açúcar no estado de São Paulo: o exemplo de Iracemápolis. Dissertação de Mestrado, Faculdade de Filosofia, Letras e Ciências Humanas, Universidade de São Paulo - São Paulo, 2001.

Diário Oficial do Estado de São Paulo - Lei 11.241 (19/09/02)

FARIELLO, D.; OLIVEIRA, E. A um Triz do Racionamento. In: O Globo, Rio de Janeiro, 03/09/12, pp. 17.

NEVES, M. F.; CONEJERO, M. A. A Estratégia para a Cana no Brasil: um negócio classe mundial. Ed. Atlas, São Paulo, 2010.

União da Indústria de Cana-de-Açúcar - http://www.unica.com.br/ (acessado em 27/08/12)

WAGNER, M. N. L. O Amargo Doce da Cana - Em Torno do Enfoque da Sustentabilidade do Desenvolvimento. Ed. EDUFAL, Alagoas, 2000.

ZANCUL, A. O efeito da Queimada de Cana-de-açúcar na Qualidade do Ar na Região de Araraquara. Dissertação de mestrado, Escola de Engenharia São Carlos, Universidade de São Paulo, São Carlos, 1998. 